\title{
Seaport efficiency and productivity based on Data Envelopment Analysis and Malmquist Productivity Index
}

\author{
Joanna BARAN ${ }^{*}$, Aleksandra GÓRECKA ${ }^{1}$ \\ 1 Warsaw University of Life Sciences - SGGW, Faculty of Economic Sciences, Warsaw, Poland
}

\begin{abstract}
Seaport efficiency and productivity are the critical factors for handling of goods in the international supply chains and plays an important role in trade exchange with other countries. It is important to evaluate efficiency and productivity of seaports to reflect their status and reveal their position in competitive environment. The main purpose of this article is to use Data Envelopment Analysis and Malmquist Productivity Index to measure the technical efficiency and total factor productivity of container ports. DEA analysis enables one to assess how efficiently a seaports uses the available inputs to generate a set of outputs relative to other units in the data set. This article presents the use CCR and BCC DEA model, to determine overall technical efficiency, pure technical efficiency and scale efficiency of container ports. The analysis gives a possibility to create a efficiency ranking of seaports. The study also applies the Malmquist Productivity Index (MPI), which was used to analyze changes in seaports productivity. The study indicated that technological progress had a greater impact on the change in productivity of container ports than changes in technical efficiency
\end{abstract}

Keywords: Malmquist Productivity Index, seaports, efficiency, productivity

\section{INTRODUCTION}

Seaports always play a strategic role in the development of domestic and international trade of a country whether it is a developing or developed country. However, in a globalized world where distances are becoming squeezed, ports play an active role in sustaining the economic growth of a country [1].

According to Cullinane et al. (2002) "Efficiency is a main issue in contemporary port economics, on grounds of port's strategic position in connecting inside the country" [2]. Port efficiency is highly correlated with handling cost. Countries with inefficient seaports have higher handling costs. The clear negative relationship shows that countries where ports are considered the most efficient are at the same time the ones whose ports charge the least for their services [3].

As critical international logistics facilities, container ports have been playing increasingly important role in national economies in the world. Transportation of goods in containers by sea has been the most important for round the world trade exchange and so port systems must have been heavily intensified in the recent decades. Financing new port development projects is highly capital intensive. A recent study of the scale of future infrastructure demand examined nine economies (Brazil, China, France, Germany, India, Japan, Mexico, the United Kingdom, and the United States), collectively accounting for $60 \%$ of world GDP, and found that their annual spending on long-term investment totaled $\$ 11.7$ trillion for the year 2012.

Container port throughput is usually measured in the number of TEUs moved. In 2011, the container throughput for developing economies grew by an estimated $8 \%$ to 406.9 million TEUs. This growth is lower than the $15.8 \%$ seen in the previous year, when businesses restocked inventories depleted because of uncertainties surrounding the global economic crisis. The growth rate for container throughput in developing economies for 2012 is still weak, estimated at $4.8 \%$.

There have been hardly papers interested comparing the biggest world container ports. The issue of seaports efficiency is usually considered in literature from a one-dimensional perspective, using conventional economic indicators, such as: labor productivity or asset productivity. One the other hand the use of non-parametric methods for the assessment of the efficiency of seaport is also a very popular direction of research. 
The purpose of this article is to use the Data Envelopment Analysis method and Malmquist Productivity Index to compare the technical efficiency and changes in productivity of container ports. The assumption is that as a result of the research a ranking would be created, seaports with a high efficiency would be indicated. A decomposition of calculated Malmquist indices has made it possible to identify what factors (technical efficiency or technological progress) determined the change in seaports productivity in 1996-2012.

\section{REVIEW OF LITERATURE}

There are two main research lines on seaport performance: the productivity evaluation approach and the efficiency evaluation approach. Whereas productivity considers actual infrastructure outputs, efficiency takes into account the maximum potential output which can be produced with the available inputs.

In shipping industry, port container terminal productivity can be measured in two types of operations. First is the vessel operation, which involves discharge and loading of container onto vessel. The other one is receiving and delivering operations, where containers transfer to and from outside trucks [4]. In addition, productivity in port container operation is key determinant for the cost of providing container stevedoring services.

Meyrick and associates and Tasman Asia Pacific (1998) report, there are two partial productivity measures have been used in port productivity studies [5]. First is annually lifts per employee (labor productivity), and it is defined as the number of container movements (container lifts) per terminal employee. The other is net crane rate (capital productivity), and it is defined as the number of container movements (container lifts) per net crane hour. This is the key word of an efficient container terminal to show to the stakeholders for high productivity [6].

On the other hand full efficiency is attained by any port container if and only if none of its inputs or outputs can be improved without worsening some of its other inputs or outputs.

Many researchers have used various approaches to evaluate seaport efficiency. There are numerous studies on port performance with Data Envelopment Analysis (DEA) and Stochastic Frontier Analysis (SFA). For example, Roll and Hayuth (1993) apply a DEA model to measure the efficiency of twenty seaports [7]. Tongzon (2001) investigates the efficiency of sixteen international seaports [8]. Bonilla et al. (2002) employ DEA in order to measure the commodities traffic efficiency of the seaports in Spain [9]. Barros (2003) utilizes DEA in Portuguese seaports and finds that the reform made by the authorities does not fulfil the targets [10]. Similarly, Barros and Athanassiou (2004) compared the efficiency of seaports in Portugal and Greece and provided benchmarks [11]. Cullinane et al. (2004) used a DEA window analysis in order to achieve more robust results [12]. Estache et al. (2004) applied the Malmquist Productivity Index (MPI) to examine if seaport liberalization was a success in Mexico [13]. Pang (2006) analyzed and evaluated 50 major ports in China by using DEA and dynamically evaluated their efficiency based on 3 years of consecutive data [14]. Park and De (2004) used a four-stage DEA to investigate the efficiency of the North American seaport Infrastructure productivity from 1984 to 1997 [15]. Min and Park (2008) proposed a hybrid DEA-simulation model to evaluate the relative efficiency of major container terminals in South Korea [16]. Wu and Lin (2008) performed an international comparison of logistic port operations with a focus on India [17]. Ablanedo Rosas and Ruiz-Torres (2009) used DEA to evaluate the efficiency of cargo and cruise operations in major Mexican ports [18]. Ablanedo-Rosas et al (2010) used a financial ratio-based data envelopment analysis to examine the relative efficiency of 11 major Chinese ports[19].

The purpose of this article is to use the Data Envelopment Analysis method and Malmquist Productivity Index to compare the technical efficiency of the world leading container ports and measure the changes in productivity of major container ports.

\section{METHODS}

Data Envelopment Analysis (DEA) is a non-parametric mathematical programming approach for measuring relative efficiencies of comparable DMUs (Decision Making Units) with respect to multiple inputs and outputs [20]. Charnes, Cooper, and Rhodes described DEA as a "mathematical programming model applied to observational data that provides a new way of obtaining empirical 
estimates of relations, such as the production functions and/or efficient production possibility surfaces, that are cornerstones of modern economics" [20]. The efficiency score in the presence of multiple input and output factors is presented mathematically in the following manner [20]:

$$
\max \frac{\sum_{k=1}^{s} u_{k} y_{k p}}{\sum_{j=1}^{m} v_{j} x_{j p}} ; \quad \frac{\sum_{k=1}^{s} u_{k} y_{k i}}{\sum_{j=1}^{m} v_{j} x_{j i}} \leq 1 \quad ; \quad u_{k}, v_{j} \geq 0 \quad \forall k
$$

where:

$s$ - quantity of outputs,

$m$ - quantity of inputs,

$U_{k}$ - weights denoting the significance of respective outputs,

$v_{j}$ - weights denoting the significance of respective inputs,

$y_{k i}$-amount of output of k-th type in i-th object,

$x_{\mathrm{ji}}$ - amount of input of $\mathrm{j}$-th type in i-th object.

Each DMU selects input and output weights that maximize its efficiency score. In general, a DMU is considered to be efficient if it obtains a score of 1 while a score of less than 1 implies that it is inefficient.

The DEA models may be categorized based on two criteria: model orientation and type of returns to scale. Depending on the model orientation a calculation is made of technical efficiency focused on the input minimization or of technical efficiency focused on the output maximization. But taking into account the type of returns to scale the following models are distinguished: the CCR model providing for constant returns to scale [20] and the BCC model providing for changing return to scale [21]. The CCR model (the name derives from the authors of the model: Charnes-CooperRhodes) is built on the assumption of constant returns to scale: this means that inputs and output are linked in a strictly proportional manner. The CCR efficiency scores measure the overall technical efficiency. The Banker-Charnes-Cooper (BCC) model is an extension of the CCR model and allows for the fact that the productivity at the most productive scale size may not be attainable for other scale sizes at which a given DMU is operating. Therefore, the BCC model estimates the pure technical efficiency of a DMU at a given scale of operation. The only difference between the CCR and BCC models is the convexity condition of the BCC model, which means that the frontiers of the BCC model have piecewise linear and concave characteristics, which lead to variable returns-toscale.

With the overall CCR and BCC model calculated, it is possible to determine the object scale efficiency (Scale Efficiency - SE). The scale efficiency is defined as a ratio of DMUs overall technical efficiency (TE) score (measured by the CCR-model) and pure technical efficiency (PTE) score (measured by the BCC model), according to the formula: SE = TE/PTE. Scale efficiency (SE) calculated in this manner denotes the degree to which the object is efficient in relation to the optimum enabling the maximal use of inputs.

Malmquist Productivity Index (MPI) is the most frequently used approach to quantification of changes in total factor productivity. MPI first introduced by Malmquist [22] has further been studied and developed in Färe et al. [23, 24]. Färe et al. [23] constructed the DEA-based MPI as the geometric mean of the two Malmquist productivity indices of Caves et al. [25] - one measures the change in technical efficiency and the other measures the shift in the frontier technology.

$$
M\left(y_{t+1}, x_{t+1}, y_{t}, x_{t}\right)=\underbrace{\frac{D^{\dagger}\left(y_{t+1}, x_{t+1}\right)}{D^{\dagger}\left(y_{t}, x_{t}\right)}}_{E F C H^{t+1}} \times \underbrace{\frac{D^{\dagger}\left(y_{t+1}, x_{t+1}\right)}{D^{t+1}\left(y_{t+1}, x_{t+1}\right)} \times \frac{D^{\dagger}\left(y_{t}, x_{t}\right)}{D^{t+1}\left(y_{t}, x_{t}\right)}}_{\text {TECH }}
$$


where:

$x_{t}$ and $x_{t+1}$ are input vectors of dimension $I$ at time $t$ and $t+1$, respectively. $y_{t}$ and $y_{t+1}$ are the corresponding k-output vectors. $D^{t}$ and $D^{t+1}$ denote an input - oriented distance function with respect to production technology at $t$ or $t+1$, which is defined as:

$D(x, y)=\max \{\rho:(s / \rho s \in L(y)\}$

where $L(y)$ represents the number of all input vectors with which a certain output vector $y$ can be produced, that is, $L(y)=\{x: y$ can be produced with $x\}$. $\rho$ in eq. (3) can be understood as a reciprocal value of the factor by with the total inputs could be maximally reduced without reducing output.

$M$ measures the productivity change between periods $t$ and $t+1$, productivity declines if $M<1$, remains unchanged if $M=1$ and improves if $M>1$. The first term on the left hand side captures the change in technical efficiency change (EFCH) between periods $t$ and $t+1$. EFCH $>1$ indicates that technical efficiency change improves while $\mathrm{EFCH}<1$ indicates efficiency change declines. The second term measures the technology frontier shift (TECH) between periods $t$ and $t+1$. A value of TECH $>1$ indicates progress in the technology, a value of TECH $<1$ indicates regress in the technology. TECH $=1$ indicates no shift in technology frontier. The technical efficiency change can further be decomposed into scale efficiency change and pure technical efficiency change [23].

Computational experiments have been carried out with the application of DEA method implemented in the specialized software called DEA SolverPro6.

\section{RESULTS}

The sample comprises the 18th world leading container ports ranked in 2012 . This sample size was determined as a function of data availability and in line with recommendations on the minimum sample size required to estimate the number of parameters in the DEA models being tested (the minimum number of DMU observations should be three times greater than the total number of inputs and output). Based on data availability, the ports are listed below according to the regions where they are located:

- Asia: Singapore, Port Klang, Port of Tanjung Pelepas, Hong Kong, Shenzhen, Ningbo, Guangzhou, Qingdao, Kaohsiung, Tianjin, Xiamen, Dalian, Shanghai, Busan,

- Europe: Antwerp, Rotterdam, Hamburg,

- USA: Los Angeles.

Since the main activity of container ports is handling containers only one output will be identified in this study and four variable input factors:

- input $x_{1}$ - number of berths (total number of berths of all terminals);

- input $x_{2}$ - terminal area (total terminal area in $m^{2}$ );

- input $x_{3}$ - storage capacity (total storage capacity of all terminals in TEU);

- input $x_{4}$ - quay length (total quay length in $\mathrm{m}$ );

- output $y_{1}$ - annual throughput (annual port throughput in TEU).

DEA models can be distinguished according to whether they are input- or output-oriented. The former is closely related to operational and managerial issues, whilst the latter is more related to planning and macroeconomic strategies. Both orientations have their usefulness in the container port industry context. With rapid expansion of global business and international trade, many container ports must frequently review their capacity in order to ensure that they can provide satisfactory services to port users and maintain their competitive edge. Sometimes, the need to build a new terminal or increase capacity is inevitable. However, before a port implements such a plan, it is of great importance for the port to know whether it has fully used its existing facilities and that output has been maximised given the input. From this point of view, the output-oriented model provides a benchmark for the container industry. Finally, it has been decided that output-oriented models should be chosen as the basis for the analysis undertaken herein.

Next section presents the results of the two stage analysis of ports. In the first stage, the results of the DEA models used for the efficiency measurement of container ports under study are analyzed. 
In the second stage, the results of the MPI models used for the productivity measurement are presented.

Table 1 indicates the CCR and BCC models which are used to evaluate 18 container ports. In 2012 , the average overall technical efficiency (CCR model) score is 0.855 . While decompose it into the pure technical (BCC model) and scale efficiencies, their average scores are 0.925 and 0.924 respectively.

Respectively, 6 and 12 out of the 18 container ports included in the analysis are identified as efficient when the DEA-CCR and the DEA-BCC models are applied. This result is not surprising since a DEA model with an assumption of constant returns to scale provides information on pure technical and scale efficiency taken together, while a DEA model with the assumption of variable returns to scale identifies technical efficiency alone. The relative role of pure technical inefficiency and scale effects on the total technical efficiency of container ports can be more easily explained through the graphical illustration of the corresponding CCR and BCC scores as data pairs on a twodimensional graph (see Fig. 1). This graph is divided into four regions, according to a line vertical to the $\mathrm{x}$-axis which denotes the average BCC score (0.925) and a line representing the average scale efficiency ( $S E=0.924)$, that is, CCR Efficiency $=S E^{*} B C C$ Efficiency $=0.924 * B C C$ Efficiency. The ports located at the upper-right part of the graph have both high pure technical and scale efficiency scores, which implies that they can well exploit their facilities and serve a large amount of containers (TEUs). The ports located at the lower-right part of the graph have high pure technical efficiency but relatively low (compared to the average value) scale efficiency. Although these ports well manage their facilities, they are subject to scale effects as they are not able to adequately accommodate the volume of containers arrived at them. The ports located at the upper-left part of the graph have relatively low pure technical efficiency but relatively high scale efficiency. These ports accommodate a large number of containers with limited performance, as they do not efficiently manage their resources. The ports located at the lower-left part of the graph have both relatively low pure technical efficiency and scale efficiency. Namely, these ports serve IOW TEU traffic with inefficient use of their facilities. Thus, they need to improve their competitive position by attracting more containers as well as better managing their resources.

With the information about the returns to scale properties of the individual terminal production yielded by DEA-BCC model, in 2012, 7 out of the 18 samples exhibits increasing returns to scale, only 3 exhibits decreasing returns to scale. Indeed, the eight terminals showed constant returns to scale (tab. 1).

Table 1. The technical efficiency, scale efficiency and returns to scale of container ports in 2012

\begin{tabular}{|l|c|c|c|c|}
\hline \multicolumn{1}{|c|}{$\begin{array}{c}\text { DMU } \\
\text { (Container ports) }\end{array}$} & $\begin{array}{c}\text { CCR-model } \\
\text { Technical } \\
\text { efficiency }\end{array}$ & $\begin{array}{c}\text { BCC-model } \\
\text { Pure technical } \\
\text { efficiency }\end{array}$ & $\begin{array}{c}\text { SE } \\
\text { Scale Efficiency }\end{array}$ & $\begin{array}{c}\text { RTS } \\
\text { Return to Scale }\end{array}$ \\
\hline Singapore & 0,92 & 1,00 & 0,92 & Decreasing \\
\hline Shanghai & 1,00 & 1,00 & 1,00 & Constant \\
\hline Hong Kong & 0,92 & 1,00 & 0,92 & Decreasing \\
\hline Shenzhen & 1,00 & 1,00 & 1,00 & Constant \\
\hline Ningbo & 1,00 & 1,00 & 1,00 & Constant \\
\hline Rotterdam & 1,00 & 1,00 & 1,00 & Constant \\
\hline Hamburg & 0,44 & 0,47 & 0,93 & Decreasing \\
\hline Busan & 0,90 & 0,91 & 0,99 & Increasing \\
\hline Antwerp & 1,00 & 1,00 & 1,00 & Constant \\
\hline Guangzhou & 0,81 & 0,83 & 0,98 & Constant \\
\hline Qingdao & 0,89 & 0,92 & 0,97 & Constant \\
\hline Kaohsiung & 0,81 & 1,00 & 0,81 & Increasing \\
\hline Tianijn & 1,00 & 1,00 & 1,00 & Constant \\
\hline Port Klang & 0,66 & 0,73 & 0,91 & Increasing \\
\hline Tanjung Pelepas & 0,88 & 1,00 & 0,88 & Increasing \\
\hline
\end{tabular}




\begin{tabular}{|l|c|c|c|c|} 
Xiamen & 0,89 & 1,00 & 0,89 & Increasing \\
\hline Dalian & 0,67 & 0,80 & 0,84 & Increasing \\
\hline Los Angeles & 0,60 & 1,00 & 0,60 & Increasing \\
\hline Average & $\mathbf{0 , 8 5 5}$ & $\mathbf{0 , 9 2 5}$ & $\mathbf{0 , 9 2 4}$ & \\
\hline
\end{tabular}

Source: Own calculations

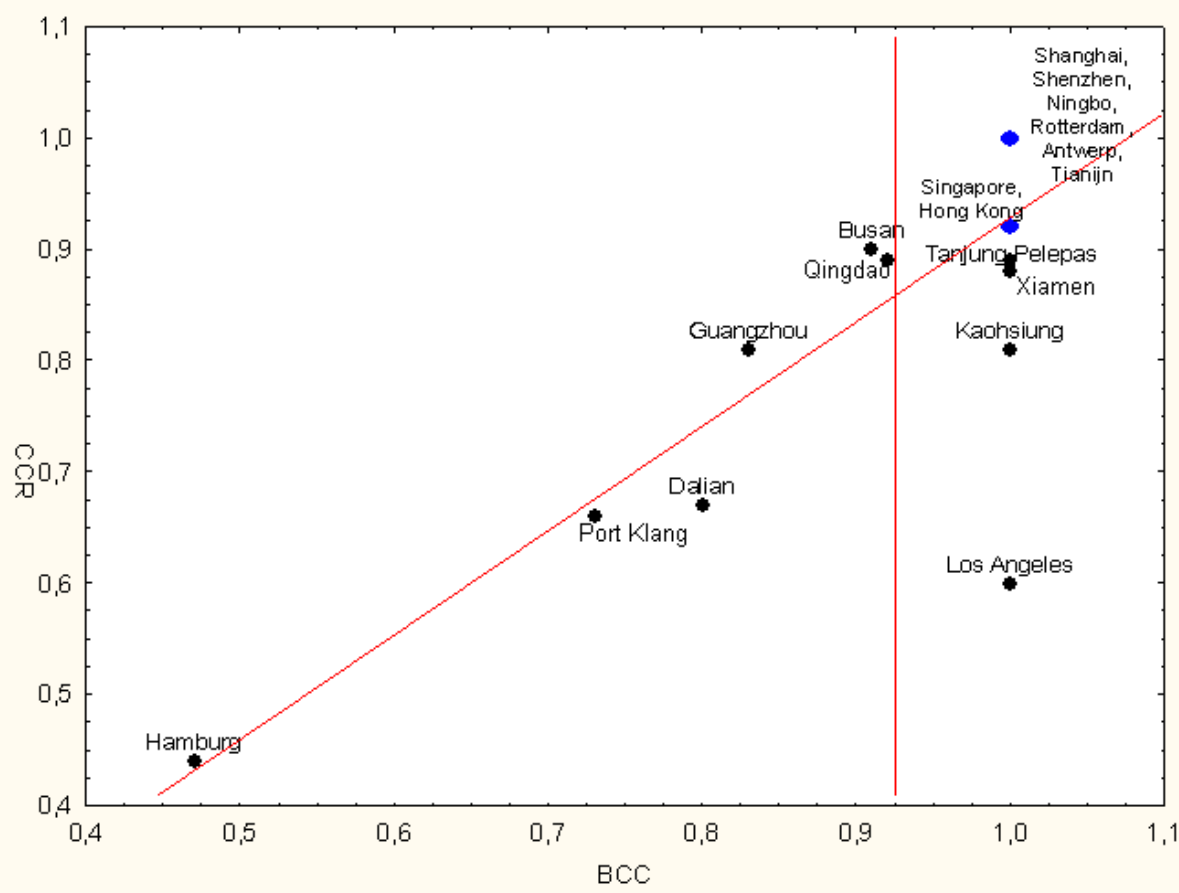

Figure. 1. Graphical illustration of container port efficiency Source: Own calculations

In the next step, four ports (Singapore, Hong Kong, Rotterdam, Hamburg) were selected for the analysis of changes in productivity in the years 1996-2012. The Malmquist Productivity Index is a tool that allows changes in total productivity to be determined and decomposed into each of their components. The average annual growth of the MPI for the four container ports amounted to $35 \%$ in the period covered by the study. The increase of the Malmquist Index was influenced primarily by changes in the technology employed. The average growth of the technological change index (TECH) was $31 \%$ for this period. In turn, the average change of the technical efficiency index (EFCH) was $3 \%$ for the studied period.

When analysing the average level of the Malmquist Index (MPI) in individual container ports one should consider that all ports improved overall productivity over the studied period. The highest average annual increase in productivity was recorded in the following container ports: Rotterdam (57\%) and Hong Kong (36\%) (Figure 2). 


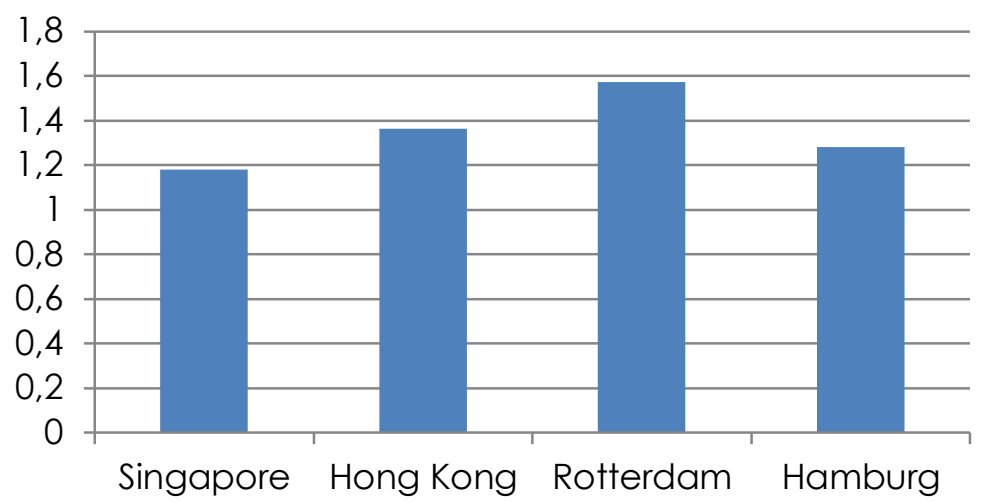

Figure 2. Average annual Malmquist Productivity Index (MPI) calculated for selected container ports Source: Own calculations

There are two indicators which have influenced and characterised MPI for Singapore, Hong Kong, Hamburd and Rotterdam: changes in technical efficiency (EFCH) and changes in technology (TECH).

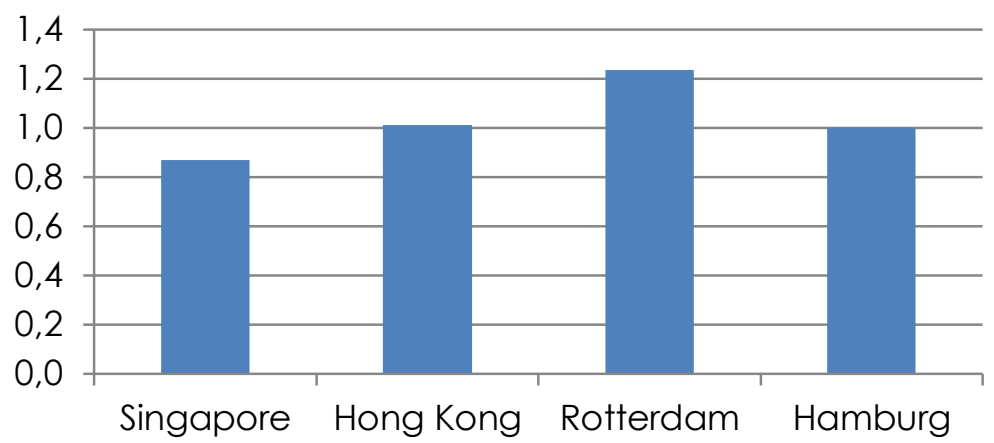

Figure 3. Changes in technical efficiency (EFCH) for researched container ports Source: Own calculations

The highest average indices of changes in technical efficiency were recorded in the Rotterdam (24\%). In turn, the lowest (less than 1) annual average indices of changes in efficiency were observed in the Singapore seaport (Figure 3).

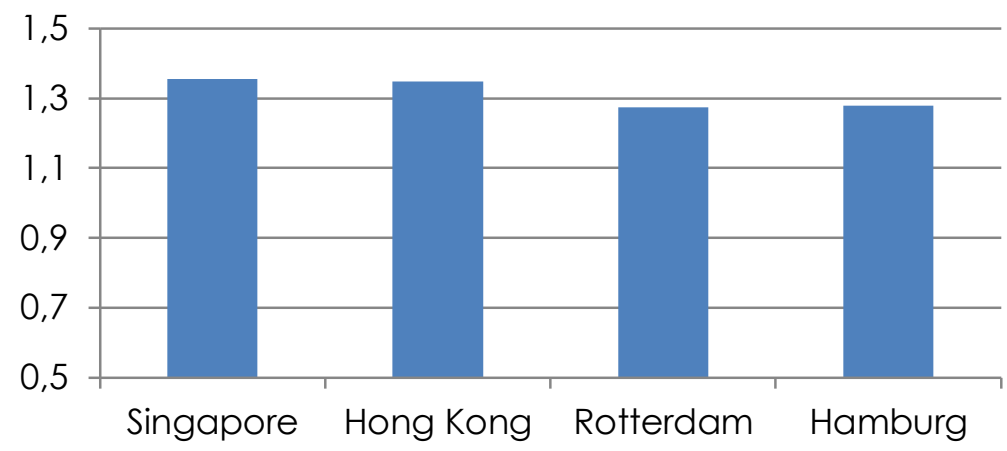

Figure 4. Changes in technology (TECH) for researched container ports Source: Own calculations

The largest average annual increases in the index of technological change (TECH) were recorded in Singapore (36\%). One might also assume the least significant level of technological progress was made in the European seaports (Figure 4). 


\section{CONCLUSION}

Changes in international production networks and maritime transport lead to a growing importance of container ports as nodes in international supply chains. For the container terminals in the competitive circumstances, productivity and efficiency is an important concept and concerned with how to use limited resources more economically for any sort of production. To meet user demands on time, cost and service, evaluating efficiency of container terminals has been recognized. As a benchmarking approach to study efficiency, DEA enables a terminal to evaluate its performance from each other in DMUs. By doing this, the possible waste of resources and the industry best practice can be identified.

The result CCR and BCC models shows that the average of efficiency scores are 0.885 and 0.925 respectively, and Shanghai, Shenzhen, Ningbo, Rotterdam, Antwerp, Tianijn ports demonstrates the best performance in each model. Furthermore, return to scale approach is used to assess whether each terminal is in a state of increasing, decreasing, or constant return to scale. The results of this study can provide container terminal managers with insights into resource allocation and optimization of the operating efficiency.

The paper also uses Malmquist Productivity Index to determine and analyze the productivity changes and its decomposition in four container terminals during 1996-2012. The major source of productivity growth to be technological progress, rather than an improvement in technical efficiency.

From the methodological point of view the proposed approach for ranking DMU has a universal character and can be applied in different industries. It allows comparing relative efficiency of DMU by determining the efficient DMUs as benchmarks and measuring the main factors which determined changes in productivity.

\section{REFERENCES}

1. G. N. Okeudo, Measurement of Efficiency Level in Nigerian Seaport after Reform Policy Implementation. Case Study of One and Rivers Seaport, Nigeria, IOSR Journal of Business and Management, Volume 12, Issue 5 (Jul. - Aug. 2013), pp. 46-55.

2. K.P.B. Cullinane, D.-W. Song, R. Gray, A stochastic frontier model of the efficiency of major container terminals in Asia: assessing the influence of administrative and ownership structures. Transportation Research A: Policy and Practice 36, 2002, pp. 743-762.

3. X. Clark, D. Dollar, A. Micco, Port efficiency, maritime transport costs, and bilateral trade, Journal of Development Economics 75 (2004), pp. 417- 450.

4. K. H. Kim, K. T. Park, A Note on A Dynamic Space-Allocation Method for Outbound Containers. Journal of Operational Research. 148 (2), 2003, pp. 92-101.

5. Meyrick and Associates and Tasman Asia Pacific. Measures to Promote Effective and Efficient Container Port Practices: Marine and Ports Group of the Australian Transport Council (1998).

6. K. Mokhtar, M. Z. Shah, Malmquist Productivity Index for Container Terminal, European Journal of Business and Management, Vol.5, No.2, 2013.

7. Y. Roll, Y. Hayuth, Port performance comparison applying data envelopment analysis (DEA), Maritime Policy and Management, 20(2), 1993, pp. 153-162.

8. J.K. Tongzon, Efficiency Measurement of Selected Australian and Other International Ports Using Data Envelopment Analysis, Transportation Research, Part A, 35, 2001, pp. 113-128.

9. M. Bonilla, A. Medal, T. Casasús, R. Sala, The Traffic in Spanish Ports: an Efficiency Analysis, International Journal of Economics Transport, XXIX (2), 2002, pp. 215-230.

10. C. Barros, Incentive Regulation and Efficiency of Portuguese Port Authorities, Maritime Economics\&Logistics, 5(1), 2003, pp. 55-69.

11. C. Barros, M. Athanassiou, Efficiency in European Seaports with DEA: Evidence from Greece and Portugal, Maritime Economics \& Logistic, 6, 2004, pp. 122-140.

12. K. Cullinane, D. W. Song, P. Ji, T-F. Wang, An Application of DEA Windows Analysis to Container Port Production Efficiency, Review of Network Economics, 3,2, 2004, pp. 184-206. 
13. A. Estache, B. Tovar de la Fé, L. Trujillo, Sources of efficiency gains in port reform: A DEA decomposition of a Malmquist index for México, Utility Policy, 30 (4), 2004, pp. 221-230.

14. R. Pang, Dynamic evaluation of main sea ports in mainland china based on DEA model, Economic Research Journal, 41, 2006, pp. 92-100.

15. R. K. Park, P. De, An alternative approach to efficiency measurement of seaports, Maritime Economics \& Logistics, 6, 2004, pp. 53-69.

16. H. Min, B. Park, A hybrid data envelopment analysis and simulation methodology for measuring capacity utilisation and throughput efficiency of container terminals. International Journal of Logistics Systems and Management, 4, 650-672.5, 2008, pp. 201-224.

17. Y.J. Wu, C. Lin, National port competitiveness: implications for India, Management Decision, 46, 2008, pp. 1482-1507.

18. J.H. Ablanedo-Rosas, A.J. Ruiz-Torres, Benchmarking of Mexican ports with data envelopment analysis, International Journal of Shipping and Transport Logistics, 1, 2009, pp. 276-294

19. J.H. Ablanedo-Rosas, H. Gao, X. Zheng, B. Alidaee, H. Wang, A study of relative efficiency of Chinese ports: a ratio-based DEA approach, Expert systems 27(5), 2010, pp. 349-362.

20. A. Charnes, W.W. Cooper, A. Rhodes, Measuring the Efficiency of Decision Making Units, European Journal of Operational Research, 2 (6), 1978, pp. 429-444.

21. R. D. Banker, A. Charnes, W. W. Cooper, Some Models for Estimating Technical and Scale Inefficiency in Data Envelopment Analysis, Management Science, 30, 1984.

22. S. Malmquist, Index Numbers and Indifference Surfaces, Trabajos de Estatistica, 4,1953, pp. 209-242

23. R. Färe, S. Grosskopf, B. Lindgren, P. Roos, Productivity Change in Swedish Pharmacies 1980-1989: A Nonparametric Malmquist Approach, Journal of Productivity Analysis, 3, 1992, pp.85-102.

24. R. Färe, S. Grosskopf, M. Norris, Z. Zhang, Productivity Growth, Technical Progress, and Efficiency Change in Industrialized Countries, The American Economic Review, vol. 84, no. 1, 1994, pp. 66-83. D. W. Caves, L. R. Christensen, W.E. Diewert, The Economic Theory of Index Numbers and the Measurement of Input, Output and Productivity, Econometrica, 50, 1982, pp. 1393-1414.

AUTHORS

J. Baran is with the Warsaw University of Life Sciences - SGGW, Faculty of Economic Sciences, Department of Economics and Organisation of Enterprises, Division of Economics and Engineering of Logistics Warsaw, Poland (e-mail: joanna_baran@sggw.pl).

A. Górecka is with the Warsaw University of Life Sciences - SGGW, Faculty of Economic Sciences, Department of Economics and Organisation of Enterprises, Division of Economics and Engineering of Logistics Warsaw, Poland (e-mail: aleksandra_gorecka@sggw.pl). 